\title{
Awareness on Yoga and Pranayama Practice Among College Students- A Survey
}

\author{
Vinaya Swetha. T1, Gayathri.R ${ }^{2}$ and V. Vishnu Priya ${ }^{3}$ \\ ${ }^{1}$ Undergraduate student, Saveetha Dental College and Hospitals, Saveetha Institute of \\ Medical and Technical Sciences, Saveetha University, Chennai, India. \\ ${ }^{2}$ Associate Professor, Department of Biochemistry, Saveetha Dental College and Hospitals, \\ Saveetha Institute of Medical and Technical Sciences, Saveetha University, Chennai 77, India \\ ${ }^{3}$ Professor, Department of Biochemistry, Saveetha dental college and Hospitals, Saveetha \\ Institute of Medical and Technical Sciences, Saveetha University, Chennai, India
}

\section{ABSTRACT}

To create knowledge and awareness about yoga and pranayama practice among college students. Physical activities are running have been shown to improve mood and relieve stress. However, college students often have poor levels of physical activity. This was a survey based study and was conducted on an online forum, Survey Planet. A questionnaire based study with fifteen questions were circulated among college students.This survey was carried out among 100 college students. Data was summarised as the number and percentage.The results were obtained and statistically analysed through SPSS software, chi square test was done to check the association and a p value of 0.05 was said to be statistically significant. The survey was conducted in the month of May, 2020. From this study, it was found that 50\% of the students they never practiced yoga or pranayama in their life, so they are not aware know about the benefits of yoga, main reason for is due to lack of awareness about yoga and their busy work schedule plays a major role in their inactivity. Nearly, $30 \%$ of the college students have the habit of practising yoga and pranayama regularly , and still 70\% of them are not aware about the benefits of practising yoga. From the survey it was also evident that ,males' perception towards yoga was different from females, where females preferred doing asanas in the morning, and males preferred meditation in the evening. Hence, it is important to create awareness among college students to develop the habit of practising yoga and pranayama to control their stress and other physical and mental ailments in an effective way.

KEY WORDS: YOGA, PRANAYAMA, COLLEGE STUDENTS, MEDITATION, STRESS.

\section{INTRODUCTION}

Yoga is a practice of uniting the mind and physical body as one. It combines breathing exercise, meditation, and physical positions. This combination is strongly believed

\section{ARTICLE INFORMATION}

${ }^{*}$ Corresponding Author: gayathri.sdc@saveetha.com Received 23rd July 2020 Accepted after revision 29th Sep 2020 Print ISSN: 0974-6455 Online ISSN: 2321-4007 CODEN: BBRCBA

Thomson Reuters ISI Web of Science Clarivate Analytics USA and Crossref Indexed Journal

\section{Clarivate
Analytics}

NAAS Journal Score 2020 (4.31) SJIF: 2020 (7.728)

A Society of Science and Nature Publication,

Bhopal India 2020. All rights reserved.

Online Contents Available at: http//www.bbrc.in/

Doi: http://dx.doi.org/10.21786/bbrc/13.8/184 to reduce many physical and mental ailments that are caused by stress. Participation of students in physical activity on a regular basis is one of the basic factors in maintaining proper health in modern society. Due to a sedentary lifestyle leading many health related issues, the prevalence of physical inactivity among college students calls for immediate action(Nguyen-Michel et al., 2006). Physical activity including yoga is a major key element in health improvements. The traditional expressions of yoga are firmly adapted and committed to the classic texts and expressed the concept of the eight limbs or other aspects of yoga.

Stress affects individuals mental health. It affects college students' mental, social, intellectual, physical health. 
College students will not always have the necessary stress overcoming skills and coping strategies. Physical activity is one coping strategy that is perhaps underutilized by many college students(Sharma, 2013). The mental and physical changes that express the efficacy of yoga to improve the stress management among college students have not been studied properly. Yoga reduces stress and eliminates negative effects among college students, improves mental health in them.

Yoga holds potential as a self-empowering, non pharmacological method for enhancing stress management, and wellness in college students(Sengupta, Chaudhuri and Bhattacharya, 2013). It was told that Pranayama training resulted in mental relaxation and decreased autonomic arousal, decreasing fluctuations at the time of isometric contraction(Vempati and Telles, 2002). It was found that it was a significant alteration in autonomic functions and mental status in both premenstrual phase when compared with postmenstrual phase among healthy females.

Yoga plays a major role in the management of hypertension, yoga together with relaxation, biofeedback, transcendental meditation, and psychotherapy, has been found to have a convincing antihypertensive effect(Anand, 1999). The mechanism of yoga and pranayama stimulate the blood pressure reduction and may contribute to beneficial effects on autonomic neurological function. Yoga asanas such as head up and head down tilt were found to be helpful in reducing hypertension. Many tests proved that improved renin angiotensin activity because of yoga practice. Yogic practice, through the restoration of baroreceptor sensitivity, caused a significant reduction in the blood pressure of patients who participated in yoga exercise(Brabant et al., 1986; Shetty, 2016).

It plays an important role in coronary atherosclerosis, Serum cholesterol levels show higher reduction as compared with control groups. It is evident in recent studies that yoga can control LDL cholesterol(Chitra, Krishna Reddy and Balakrishna, 2012) and hypertension. Revascularization procedures are required very less frequently in yoga practice. Follow up angiography after 1 year shows significantly more lesions regressed in yoga practice compared with control groups. Yoga exercise retards progression of atherosclerosis(Manchanda et al., 2003).

Obesity is a risk factor for many ischemic heart disease and hypertension. Yoga is very much helpful in the management of obesity. A study said that practicing yoga helped improvements in body weight(Chopra, 2012). Respiratory muscles are also similar to skeletal muscles. Yoga practice brings isometric contraction which increases skeletal strength. Breath holding techniques time depends on the amount of initial lung volume. Higher lung volume lowers the frequency and amplitude of the involuntary contractions of the respiratory muscles. Yoga practice results in an increase in maximum expiratory pressure, breath holding time after expiration, hand grip strength(Francina, 2010).
Yoga and pranayama practice plays a very major role in diabetic patients, Yoga is a simple and useful therapeutic modality that is considered as a beneficial therapy for non insulin dependent diabetes mellitus patients. In a population of diabetics who used to practice yoga regularly, there was a significant reduction in the effect of hyperglycemia in the oral glucose tolerance test curve. This experimental study showed that there was also a decrease in the need for oral hypoglycemic to maintain adequate blood sugar control in the population that practiced yoga(Jain et al., 1993).

Many studies have said women practicing yoga in their second trimester has significant reductions in physical pain. Women in their third trimester showed greater reductions in perceived stress and trait anxiety. From this, it is clear that yoga can be used to prevent or reduce obstetric complications(Beddoe et al., 2009).

Stress becomes a serious health issue nowadays because it affects physical and mental health of an individual. In yoga and pranayama activities such as relaxation, and exercise and meditation. As it appears as a good method to reduce stress and anxiety, yoga becomes a healthy measure to modulate stress response systems. This leads to decreasing physiological arousal such as low blood pressure, reducing heart rate. It has been said that individuals trained in yoga can achieve a state of deep psychosomatic relaxation associated with significant decrease in oxygen consumption within 5 min of practicing savitri pranayama(Nivethitha, Manjunath and Mooventhan, 2017).

Earlier reviews have reported that yoga is beneficial for people with cancer in managing symptoms such as fatigue, insomnia, mood disturbances and stress, and improving quality of life. Many cancer patients have experienced cancer related psychological symptoms, which includes stress(DiStasio, 2008). According to Carson's study of yoga for women with metastatic breast cancer,(Cohen et al., 2004) patients who practiced yoga longer are likely to experience relaxation themselves. Thus yoga and pranayama practice helps in maintaining an individual's total body mechanism in a proper state and also very helpful in controlling one's stress and anxiety to avoid mental problems.

Health experts told that after two months practicing pranayama medical students had reduced stress levels, and led to a decrease in stress score, highly significant, at the initial part of the study(Dhanvijay and Chandan, 2018). School-based yoga interventions may improve several factors that are relevant to academic performance, such as emotional balance, attentional control, cognitive efficiency, and a number of positive psychosocial outcomes(Cook-Cottone, Childress and Harper, 2019). Yoga brings together physical and mental disciplines that may help achieve peacefulness of body and mind(Thanalakshmi et al., 2020). Many studies revealed that both Yoga intervention and drug treatment helped hypertensives, but yoga intervention was the most effective(Preetha and Packyanathan, 2020).Thus,this 
study has created knowledge and awareness about yoga and pranayama practice among college students.

\section{MATERIAL AND METHODS}

The sample size of this study was 100 college students. The study group consists of 68 female and 29 male participants of age group between 17 to 25 years. The study was conducted in Chennai city. This was a questionnaire-based study. The survey questionnaire was prepared and administered through the survey planet to all participants. Participants volunteered for the survey and completed the survey link. The results were obtained and statistically analysed through SPSS software, chi square test was done to check the association and a $\mathrm{p}$ value of 0.05 was said to be statistically significant. The survey was conducted in the month of May, 2020.

\section{RESULTS AND DISCUSSION}

From this study it was observed that about $71.7 \%$ of females have the habit of practising yoga than males, males only $28.28 \%$ are used to practice yoga(fig 1$)$. The main reason for more participation of females than males in yoga practice is most of the females are homemakers and they use their free time in practising yoga and they practised it as their regular habit and they used it more than males. In this study about $46 \%$ of them stated that they used to practice yoga because of their friends and family, while they chit chatting they used to talk about the benefits of yoga and pranayama, about 30\% of them experienced yoga practice by attending public events and many public programs, about $24 \%$ of them knows yoga by Tv and magazines.

Figure 1: Bar chart depicting gender distribution of the participants. It shows $28.28 \%$ were Male, $71.72 \%$ were female who took the survey.

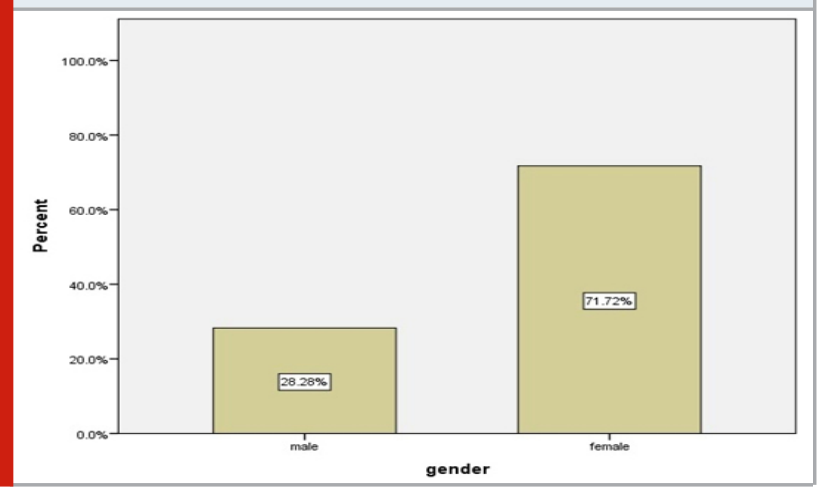

It was observed that about $75.7 \%$ of the participants did not have the habit of practising yoga the reason for this is most of them did not have the enough time for them to practice yoga in their busy schedule, about $24 \%$ of the participants have the habit of practising yoga cause they well known about the benefits of yoga and pranayama(fig 2). Yoga is very much important in maintaining stress and diet and it is very useful in preventing many cardiovascular problems, respiratory problems, and many other neurological problems.
Figure 2: Bar chart depicting distribution of yoga practice of the participants. It shows $24.4 \%$ of the participants have the habit of practising yoga, $75.76 \%$ do not have the habit of practising yoga.

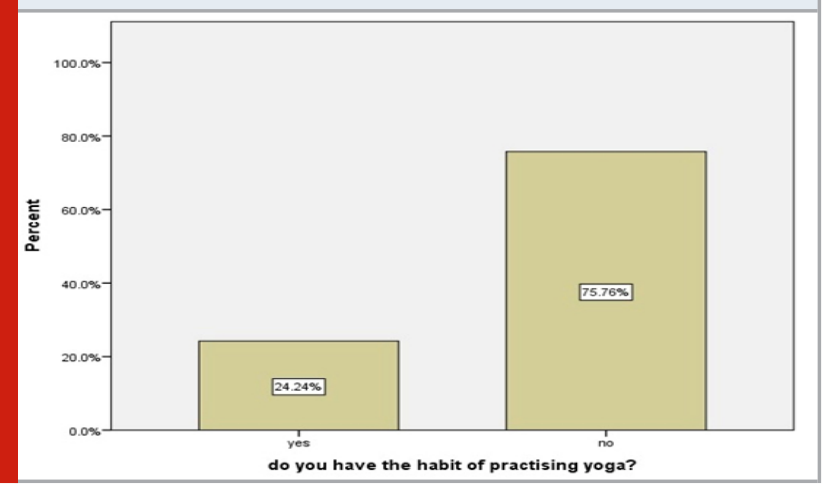

About 79.8\% of the participants stated that early morning is the best time for practising yoga, and 12\% of those stated that afternoon is the best time to practice yoga, about $6 \%$ of them stated that evening is the best time to practice yoga(fig 3). In this study about $67 \%$ of them say that they did not purchase any specific clothing for doing yoga, about 33\% of them have purchased specific clothing for doing yoga such as yoga mats, special clothings. About $74 \%$ of the participants have said that they consulted a professional therapist about yoga and 26\% of them have not involved them in any consultation.

Figure 3: Bar chart depicting distribution of participants based on the good time of choice they feel to practice yoga . It shows $79.8 \%$ prefer early morning, $12 \%$ prefer afternoon, 6\% prefer evening, $2 \%$ prefer night.

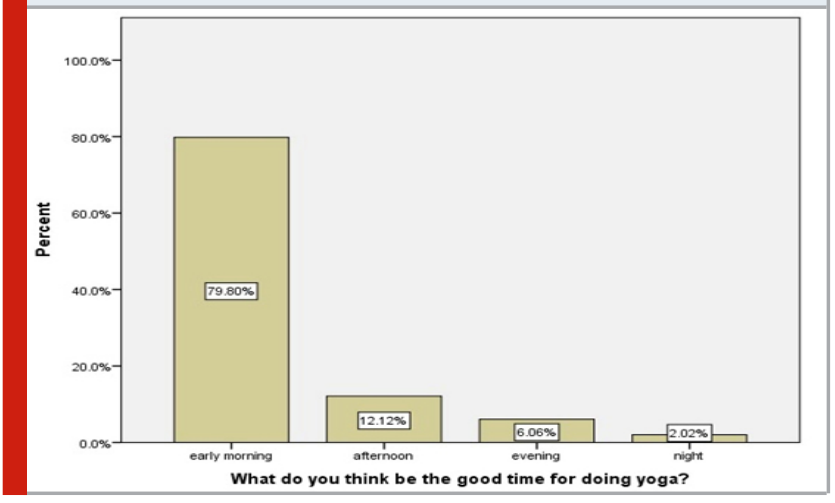

About $36 \%$ of them stated that yoga is good for the mind, 28\% of them say that it is good for the body, $23 \%$ says that it helps in once fitness, $12 \%$ says that it is good for internal organs(fig 4). About 64\% of them purchased a special yoga mat for their yoga practice, $36 \%$ of them did not purchase any yoga mat for their practice. About 51.52\% of them stated that they have not practiced yoga in their lifetime, $21 \%$ of them says they have been practising yoga for past 10 years, 15\% of them says that they have been practising yoga for past 5 years, 12\% says that they have been practising yoga for past 15 years(fig 5). 
Figure 4: Bar chart depicting distribution of participants based on the reason to practice yoga. 23.2\% practise yoga for fitness, $28.2 \%$ practice yoga to keep body fit, $12 \%$ practice yoga as it is good for internal organs, $36.3 \%$ practice yoga as it is good for mind.

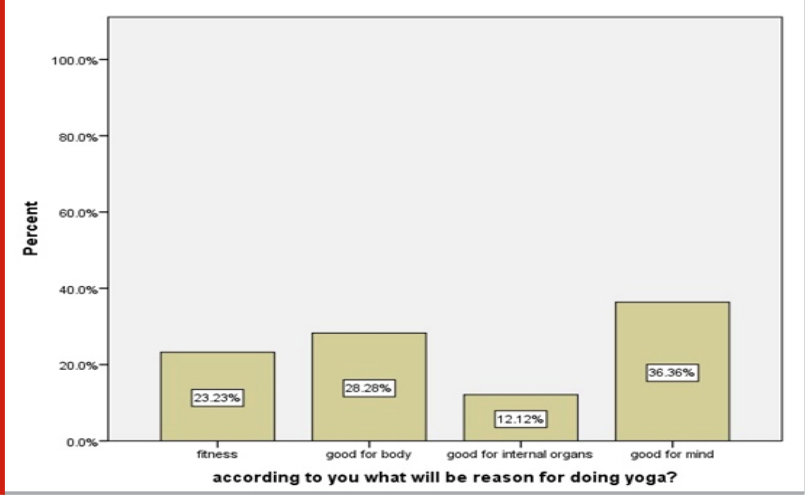

Figure 5: Bar chart depicting distribution of duration of yoga practice of the participants. It shows $15 \%$ of them practise yoga for 5 years, $21 \%$ of them practise yoga for 10 years, $12 \%$ of them practise yoga for 15 years, $51.5 \%$ of them never practiced yoga.

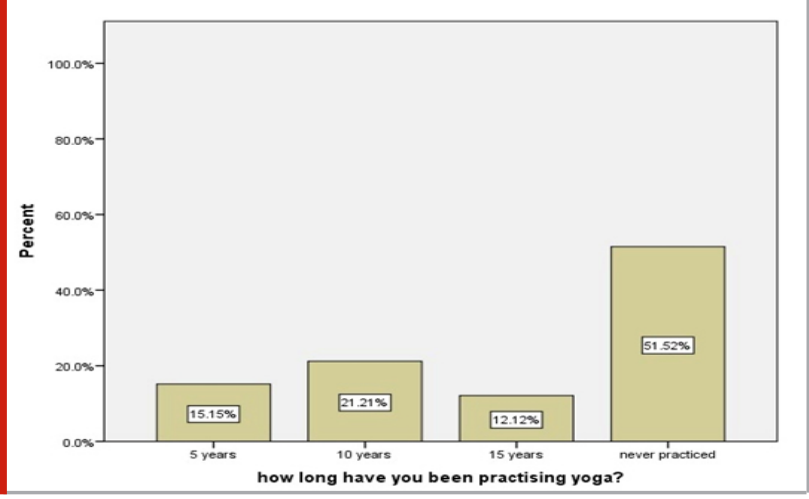

Figure 6: Bar chart depicting distribution of type of yoga practiced by the participants. It shows $34.3 \%$ of them do meditation, $20 \%$ of them do asanas, $6 \%$ of them do pranayama, 39.3\% practice meditation, asanas, pranayama.

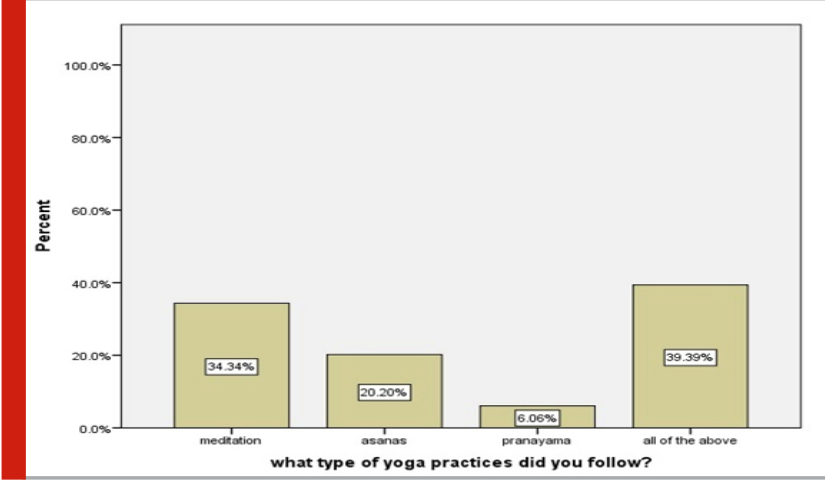

Figure 7: Bar chart represents the correlation of gender and habit of practising yoga. The $\mathrm{X}$ axis represents the question "do you have the habit of practising yoga?" and the $\mathrm{Y}$ axis represents the gender. Where the blue colour denotes "Male" and green colour denotes "Female". Females have the habit of practising yoga regularly than males . Chi square test was done and the association was found to be statistically significant (Pearson's Chi square value:80.331, $\mathrm{p}=0.00<0.05)$.

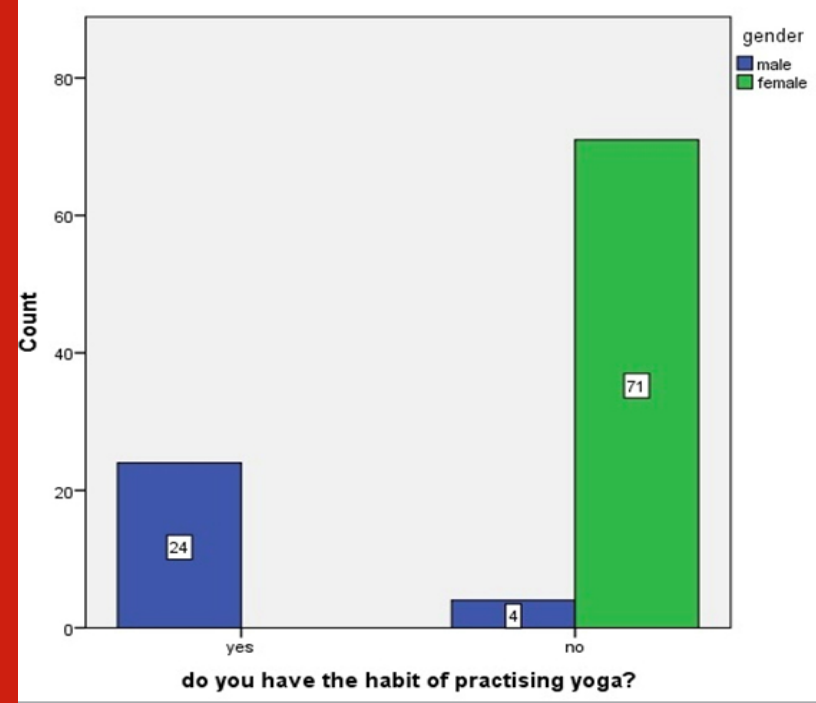

Figure 8: Bar chart represents the correlation of gender and habit of practising yoga. The $\mathrm{X}$ axis represents the question "what do you think would be the good time for doing yoga?" and the Y axis represents the gender. Where the blue colour denotes "Male" and green colour denotes "Female". Higher response for early morning yoga practice is seen among females. Chi square test was done and the association was found to be statistically significant (Pearson's Chi square value:9.884, $\mathrm{p}=\mathbf{0 . 0 2 < 0 . 0 5 ) \text { . }}$

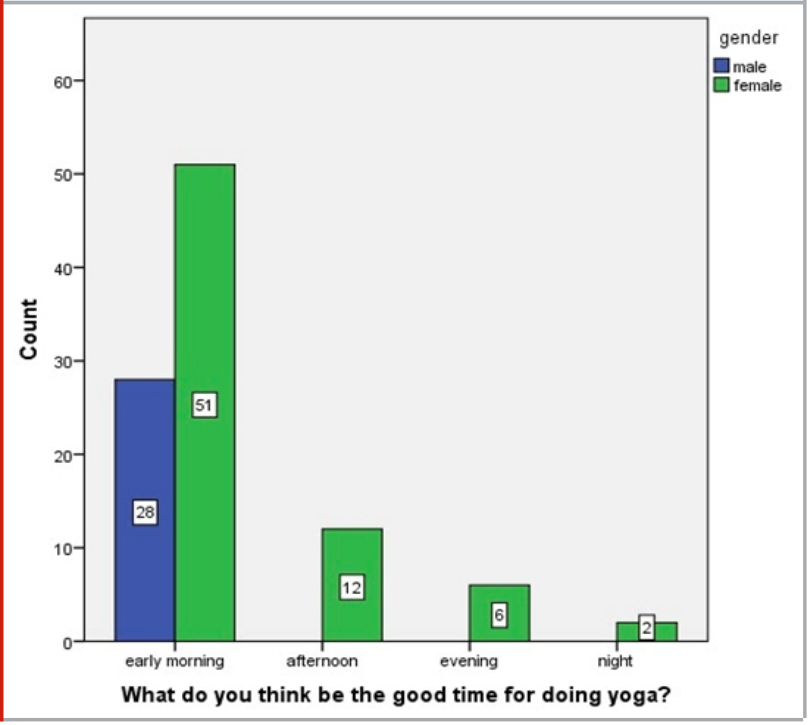


In this study $59 \%$ of the states that 1 hour is their daily yoga session, 19\% used to practice yoga for 2 hours, $22 \%$ used to practice more than 2 hours daily. About $42 \%$ of them used to do meditation, $24 \%$ used to do asanas, $7 \%$ used to do pranayama, $27 \%$ used to practice all yoga practices such as meditation, asanas, pranayama(fig 6). About 78\% of the participants are vegetarian and $22 \%$ of them are non vegetarian. About $60 \%$ maintain a healthy diet rest $40 \%$ of the participants are not maintaining a healthy diet. Females have the habit of practising yoga regularly than males and $p$ value was found to be $0.00<0.05$, statistically significant (figure 7). Higher response for early morning yoga practice is seen among females $\mathrm{p}$ value was found to be $0.02<0.05$, statistically significant(figure 8 ). Males responded higher for fitness and higher response for good for mind is seen among females and $\mathrm{p}$ value was found to be $0.00<0.05$, statistically significant(figure 9). Males have the habit of meditating, asanas are most commonly seen among females and $\mathrm{p}$ value was found to be $0.00<0.05$, statistically significant(figure 10 ).

Figure 9: Bar chart represents the correlation of gender and habit of practising yoga. The $\mathrm{X}$ axis represents the question "according to you what will be the reason for doing yoga?" and the $\mathrm{Y}$ axis represents the gender. Where the blue colour denotes "Male" and green colour denotes "Female". Males preferred yoga for keeping them fit whereas the majority of females preferred yoga as it is good for mind. Chi square test was done and the association was found to be statistically significant (Pearson's Chi square value:78.752, $\mathrm{p}=0.00<0.05$ ).

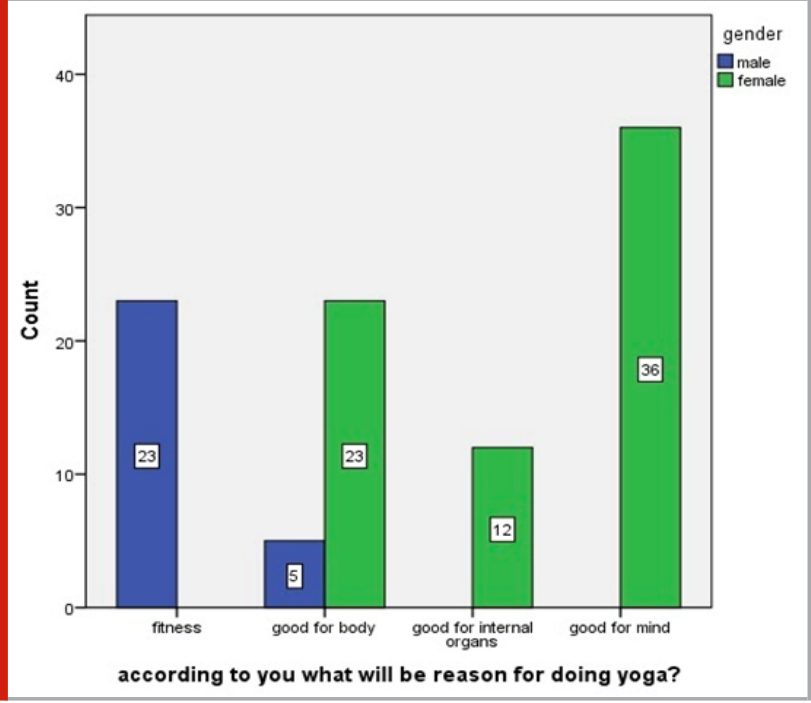

CONCLUSION

From this survey it was found that $74 \%$ of the participants did not have the habit of practising yoga, 33\% stated that practising yoga is good for mind and soul. From the survey it was also evident that ,males' perception towards yoga was different from females, where females preferred doing asanas in the morning, and males preferred meditation in the evening. Yoga and pranayama
Figure 10: Bar chart represents the correlation of gender and type of yoga practice preferred by the participants. X axis represents the question "what type of yoga practice did you follow?" and the $Y$ axis represents the number of male and female participants. Where the blue colour denotes "Male" and green colour denotes "Female". Males have the habit of meditating, whereas the majority of females prefer doing asanas. Chi square test was done and the association was found to be statistically significant (Pearson's Chi square value:74.640, $\mathrm{p}=0.00<0.05$ ).

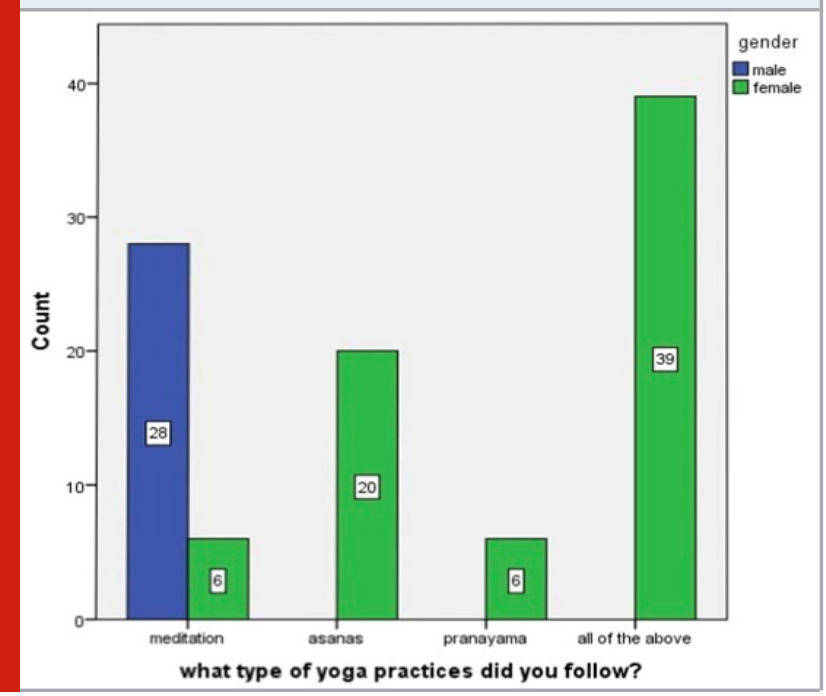

practice is very useful in maintaining a healthy lifestyle and to control cardiovascular, neurological, respiratory problems.The survey has created an awareness on the importance of practising yoga and pranayama among college students.

\section{ACKNOWLEDGEMENTS}

The authors would like to acknowledge the help and support rendered by the Department of Biochemistry and the Management of Saveetha Dental College and Hospitals for their constant assistance with the research.

Conflict of Interest: None Declared.

\section{REFERENCES}

Anand, M. P. (1999) 'Non-pharmacological management of essential hypertension', Journal of the Indian Medical Association, 97(6), pp. 220-225.

Beddoe, A. E. et al. (2009) 'The Effects of MindfulnessBased Yoga During Pregnancy on Maternal Psychological and Physical Distress', Journal of Obstetric, Gynecologic Et Neonatal Nursing, pp. 310-319. doi: 10.1111/j.15526909.2009.01023.x.

Brabant, G. et al. (1986) 'The effect of glucocorticoid administration on the circadian and episodic secretion of thyrotropin in man', Acta Endocrinologica, p. S35. doi: 10.1530/acta.0.111s035. 
Chitra, U., Krishna Reddy, N. and Balakrishna, N. (2012) 'Role of lifestyle variables on the lipid profile of selected South Indian subjects', Indian Heart Journal, pp. 28-34. doi: 10.1016/s0019-4832(12)60007-8.

Chopra, D. (2012) AARP The Seven Spiritual Laws of Yoga: A Practical Guide to Healing Body, Mind, and Spirit. John Wiley \& Sons.

Cohen, L. et al. (2004) 'Psychological adjustment and sleep quality in a randomized trial of the effects of a Tibetan yoga intervention in patients with lymphoma', Cancer, pp. 2253-2260. doi: 10.1002/cncr.20236.

Cook-Cottone, C., Childress, T. and Harper, J. C. (2019) 'Secularity: Guiding Questions for Inclusive Yoga in Schools', International Journal of Yoga Therapy, pp. 127-133. doi: 10.17761/2019-00007.

Dhanvijay, A. and Chandan, L. (2018) 'Effect of Nadi Shuddhi Pranayama on perceived stress and cardiovascular autonomic functions in 1st year undergraduate medical students', National Journal of Physiology, Pharmacy and Pharmacology, p. 1. doi: 10.5455/njppp.2018.8.0205515022018.

DiStasio, S. A. (2008) 'Integrating Yoga Into Cancer Care', Clinical Journal of Oncology Nursing, pp. 125-130. doi: 10.1188/08.cjon.125-130.

Francina, S. (2010) The New Yoga for Healthy Aging: Living Longer, Living Stronger and Loving Every Day. Simon and Schuster.

Jain, S. C. et al. (1993) 'A study of response pattern of non-insulin dependent diabetics to yoga therapy', Diabetes Research and Clinical Practice, pp. 69-74. doi: 10.1016/0168-8227(93)90146-v.

Manchanda, S. C. et al. (2003) 'Reversal of Coronary Atherosclerosis by Yoga Lifestyle Intervention', Progress in Experimental Cardiology, pp. 535-547. doi: 10.1007/978-1-4615-0455-9_39.
Nguyen-Michel, S. T. et al. (2006) 'Associations between physical activity and perceived stress/hassles in college students', Stress and Health, pp. 179-188. doi: 10.1002/ smi.1094.

Nivethitha, L., Manjunath, N. K. and Mooventhan, A. (2017) 'Heart rate variability changes during and after the practice of bhramari pranayama', International Journal of Yoga, p. 99. doi: 10.4103/0973-6131.205518.

Preetha, S. and Packyanathan, J. (2020) 'Comparison of the effect of Yoga, Zumba and Aerobics in controlling blood pressure in the Indian population', Journal of Family Medicine and Primary Care, p. 547. doi: 10.4103/ jfmpc.jfmpc_607_19.

Sengupta, P., Chaudhuri, P. and Bhattacharya, K. (2013) 'Male reproductive health and yoga', International Journal of Yoga, p. 87. doi: 10.4103/09736131.113391.

Sharma, V. K. (2013) 'Effect of Yoga on Autonomic Functions and Psychological Status During Both Phases of Menstrual Cycle in Young Healthy Females', JOURNAL OF CLINICAL AND DIAGNOSTIC RESEARCH. doi: $10.7860 /$ jcdr/2013/6912.3451.

Shetty, A. (2016) 'Yoga as Physical Therapy Intervention and Future Direction for Yoga Research', Journal of Yoga \&t Physical Therapy. doi: 10.4172/21577595.1000e122.

Thanalakshmi, J. et al. (2020) 'Effect of Sheetali pranayama on cardiac autonomic function among patients with primary hypertension - A randomized controlled trial', Complementary therapies in clinical practice, 39, p. 101138.

Vempati, R. P. and Telles, S. (2002) 'Yoga-Based Guided Relaxation Reduces Sympathetic Activity Judged from Baseline Levels', Psychological Reports, pp. 487-494. doi: 10.2466/pro.2002.90.2.487. 